\title{
Detection of glypican-3-specific CTLs in chronic hepatitis and liver cirrhosis
}

\author{
EMIKO HAYASHI ${ }^{1}$, YUTAKA MOTOMURA ${ }^{1}$, HIROFUMI SHIRAKAWA ${ }^{1}$, TOSHIAKI YOSHIKAWA ${ }^{1}$, \\ NOBUYUKI OBA ${ }^{2}$, SHUTA NISHINAKAGAWA ${ }^{2}$, YASUHIRO MIZUGUCHI ${ }^{2}$, TATSUYA KOJIMA ${ }^{2}$, \\ KAZUHIRO NOMURA ${ }^{2}$ and TETSUYA NAKATSURA ${ }^{1}$ \\ ${ }^{1}$ Section for Cancer Immunotherapy, Investigative Treatment Division, Research Center for Innovative Oncology, \\ National Cancer Center Hospital East, 6-5-1 Kashiwanoha, Kashiwa, Chiba 277-8577; ${ }^{2}$ Tokyo Rosai Hospital, \\ Department of Internal Gastroenterology, 4-13-21 Omoriminami, Ota-ku, Tokyo 143-0013, Japan
}

Received February 10, 2009; Accepted March 26, 2009

DOI: $10.3892 /$ or_00000418

\begin{abstract}
Glypican-3 (GPC3) is one of carcinoembryonic antigens known to be overexpressed in hepatocellular carcinoma (HCC). It has been suggested that GPC3 may be related to the development of HCC in a background of chronic hepatitis $(\mathrm{CH})$ and liver cirrhosis (LC). Therefore, in an attempt to establish an early diagnostic marker of HCC, we quantified the number of GPC3-specific CTLs in the peripheral blood of $\mathrm{CH}$ and $\mathrm{LC}$ patients. We selected $\mathrm{CH}$ and LC patients who were HCV-RNA (+) or HBs antigen (+) within 6 months prior to the study and had no HCC nodules as detected by imaging. A total of 56 patients with $\mathrm{CH}$ and LC, and 45 patients with HLA-A $24^{+}$or HLA-A2+ were enrolled for this investigation. After isolation of mononuclear cells from each patient's peripheral blood specimens, we performed ELISPOT assay using HLA-A24- and HLA-A2restricted GPC3 peptides. In the ELISPOT assay, GPC3specific CTLs were detected in 10 of the $45 \mathrm{CH}$ and LC cases $(22 \%)$. In addition, the plasma titers of anti-GPC3 IgG were increased in the $\mathrm{CH}$ and $\mathrm{LC}$ patients as compared with those in healthy donors. GPC3-specific CTLs were found to be present not only in patients with $\mathrm{HCC}$, but also in patients with $\mathrm{CH}$ and LC. This suggests the possibility of GPC3-
\end{abstract}

Correspondence to: Dr Emiko Hayashi or Dr Tetsuya Nakatsura, Section for Cancer Immunotherapy, Investigative Treatment Division, Research Center for Innovative Oncology, National Cancer Center Hospital East, 6-5-1 Kashiwanoha, Kashiwa, Chiba 277-8577, Japan

E-mail: ehayashi@east.ncc.go.jp tnakatsu@east.ncc.go.jp

Abbreviations: GPC3, glypican-3; $\mathrm{CH}$, chronic hepatitis; LC, liver cirrhosis; HCC, hepatocellular carcinoma

Key words: glypican-3, CTL, chronic hepatitis, liver cirrhosis, hepatocellular carcinoma specific CTLs serving as a marker for the early diagnosis of imaging-invisible HCC.

\section{Introduction}

The prevalence of hepatocellular carcinoma (HCC) is increasing rapidly in both Asian and Western countries. It is clear that patients with hepatitis B- or C-associated liver cirrhosis are at a higher risk of developing HCC (1), and patients with hepatitis treated surgically or by other therapies are also at a higher risk of recurrence (2). Furthermore, the liver function of these patients is often very poor, which restricts further treatment options for recurrence. As a result, the prognosis of HCC remains poor, and the development of new therapies for the prevention of cancer development and recurrence, that is, adjuvant therapy, is urgently needed.

Glypican-3 (GPC3) has been reported to be overexpressed in most types of HCC (3-10) and melanoma in humans $(6,8,9)$. GPC3 belongs to the six-member family of glypicans in mammals (11). GPC3 is a heparan sulfate proteoglycan that is bound to the outer surface of the plasma membrane by a glycosylphosphatidylinositol anchor. GPC3 has been shown to regulate the signaling mediated by Wnts $(12,13)$, Hedgehogs (14), fibroblast growth factors $(15,16)$ and bone morphogenetic proteins $(15,17)$. These signaling pathways are only partially dependent on the heparan sulfate chains $(11,16,18)$. However, whether GPC3 plays an oncogenic role in HCC is still controversial.

We recently identified both HLA-A24 (A*2402) and H$2 \mathrm{~K}^{\mathrm{d}}$-restricted GPC $3_{298-306}$ (EYILSLEEL) and HLA-A2 (A*0201)-restricted GPC $3_{144-152}$ (FVGEFFTDV), both of which can induce GPC3-reactive cytotoxic T cells (CTLs) (19). We previously reported a preclinical study conducted in a mouse model with a view to designing an optimal schedule for clinical trials of a GPC3-derived peptide vaccine (20). We predicted that overexpression of GPC3 in HCC is related to the development of HCC in a background of chronic hepatitis $(\mathrm{CH})$ and/or liver cirrhosis (LC). Towards establishing the possibility of early diagnosis of imaging-invisible HCC and vaccine therapy, we determined the number of GPC3-specific CTLs in the peripheral blood of $\mathrm{CH}$ and LC patients. 


\section{Materials and methods}

Patients, blood samples and cell lines. Blood samples from patients with $\mathrm{CH}$ and $\mathrm{LC}$ were collected during routine diagnostic procedures after obtaining their written consent at the Tokyo Rosai Hospital between October 2006 and October 2007. CH and LC patients who were confirmed to be HCV-RNA(+) or HBs antigen(+) within six months prior to registration were eligible for the study. The diagnosis of $\mathrm{CH}$ or LC was made clinically by imaging and laboratory data. The patients had no medical history of HCC, and no evidence of HCC on ultrasonography, CT (computed tomography) or MRI (magnetic resonance imaging) conducted prior to the registration.

Human liver cancer cell lines SK-Hep-1/GPC3, HepG2 and K562 were maintained in vitro in RPMI-1640 or DMEM supplemented with $10 \%$ FCS. SK-Hep-1/GPC3 has been described previously (19). HepG2 endogenously expressing GPC3 was kindly provided by the Cell Resource Center for Biomedical Research Institute of Development, Aging, and Cancer (Tohoku University, Sendai, Japan). HLA-class I deficient K562 was obtained from Kumamoto University. The origins and HLA genotypes of these cell lines have been described in previous reports $(21,22)$.

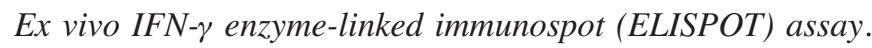
We isolated peripheral blood mononuclear cells (PBMCs) from the heparinized blood of HLA-A2 ${ }^{+}$and/or HLA-A24+ Japanese $\mathrm{CH}, \mathrm{LC}$ or HCC patients and healthy donors by means of Ficoll-Conray density gradient centrifugation. IFN- $\gamma$ production by the CTLs present in the PBMCs in the presence or absence of the GPC3 peptide was assessed by the ELISPOT assay (BD ${ }^{\text {TM }}$ Bioscience, San Diego, CA), as described previously. Briefly, defrosted PBMCs (1x10\%/well) were cultured in 96-well flat-bottomed plates for the ELISPOT assay (BD Bioscience) with HLA-A2-restricted GPC3 ${ }_{44-52}$ (A2-1) (RLQPGLKWV), GPC3 ${ }_{144-152}$ (A2-3) (FVGEFFTDV), GPC $_{155-163}$ (A2-4) (YILGSDINV) and HLA-A24-restricted $\mathrm{GPC}_{298-306}$ (A24-8) (EYILSLEEL) $(10 \mu \mathrm{M})$ with 100 units/ $\mathrm{ml}$ recombinant human IL-2 overnight in vitro. The negative control consisted of medium alone and the positive control included HLA-A24- or -A2-restricted cytomegalovirus. The number and area of the spots were automatically determined and subsequently analyzed with the ELISPOT system (Minerva Tech, Tokyo, Japan).

Induction of GPC3-reactive human CTLs and cytotoxic assay. We evaluated the cytotoxic activity of the CTLs that were induced with the GPC3 A2-3 peptide in the PBMCs isolated from the $\mathrm{CH} 4$ patient. PBMCs were isolated from HLA-A2+ $\mathrm{CH} 4$ patient, distributed into 4 wells $\left(3 \times 10^{5}\right.$ cells/24-well), and cultured with the GPC3 A2-3 peptide. After culture for 7 and 14 days, the PBMCs cocultured with irradiated autologous monocyte-derived DCs obtained by positive selection with human CD14 Micro Beads (Miltenyi, Bergisch Gladbach, Germany) were pulsed with the GPC3 A2-3 peptide. The $\mathrm{CD} 14^{+}$cells were cultured in the presence of $100 \mathrm{ng} / \mathrm{ml}$ of granulocyte macrophage colony-stimulating factor (GM-CSF) (R\&D Systems, Inc.) and $100 \mathrm{ng} / \mathrm{ml}$ of IL-4 (R\&D Systems,
Inc.) in RPMI-1640 (Sigma-Aldrich Corp., St. Louis, MO) containing $2 \%$ heat-inactivated autologous serum and $1 \%$ penicillin-streptomycin-glutamine (Gibco, Invitrogen, Ltd.; Paisley, Scotland, UK). After 5 days, TNFa (PEPRPTECH EC., London, UK) was added at the concentration of $20 \mathrm{ng} /$ $\mathrm{ml}$ to induce maturation of the DCs. After 7 days, mature DCs were harvested and pulsed with $10 \mu \mathrm{M}$ of the candidate peptides for $4 \mathrm{~h}$ at room temperature in RPMI. The peptidepulsed DCs were then irradiated (3500 rads) and mixed at a ratio of 1:20 with autologous PBMCs.

These DCs were set up in 48-well culture plates; each well contained $1.5 \times 10^{4}$ peptide-pulsed DCs, $3 \times 10^{5}$ PBMCs and $5 \mathrm{ng} / \mathrm{ml} \mathrm{IL-7} \mathrm{(PEPRPTECH} \mathrm{EC.)} \mathrm{in} 0.5 \mathrm{ml}$ of RPMI containing $10 \%$ autologous serum. Three days after the start of the incubation, IL-2 (R\&D Systems, Inc.) was added to these cultures at a final concentration of $10 \mathrm{U} / \mathrm{ml}$. On days 7 and 14 , the $\mathrm{T}$ cells were restimulated with the autologous DCs pulsed with the peptide.

After 21 days, the cells were recovered and analyzed for their cytotoxic activity against the target cells with the TERASCAN VPC system (Minerva Tech), as previously described (23). Briefly, SK-Hep-1/GPC3 $\left(\mathrm{GPC}^{+}, \mathrm{A}^{+}, \mathrm{A} 24^{+}\right)$, HepG2 $\left(\mathrm{GPC}^{+}, \mathrm{A}^{+}, \mathrm{A} 24^{+}\right)$and $\mathrm{K} 562$ (HLA-class I-) cells were used as the target cells and labeled with calcein-AM solution for $30 \mathrm{~min}$ at $37^{\circ} \mathrm{C}$. The labeled cells were washed three times and distributed into a 96-well culture plate $\left(1 \times 10^{4}\right.$ per well) and then incubated with the effector cells for $5 \mathrm{~h}$. The fluorescence intensity was measured before and after 5 -h culture, and the Ag-specific cytotoxic activity was calculated using the following formula: cytotoxicity $(\%)=[($ sample release) - (spontaneous release) $] /[($ maximum release $)$ (spontaneous release)] x 100.

ELISA for the detection of anti-GPC3 IgG antibodies. Recombinant human GPC3 protein (R\&D Systems Inc., Minneapolis, MN) was diluted in $10 \mathrm{x}$ Block Ace (Dainippon Pharmaceutical, Osaka) to a final concentration of $1 \mu \mathrm{g} / \mathrm{ml}$, dispensed into 96-well plates $(100 \mu \mathrm{l} /$ well $)$ and incubated overnight at $4^{\circ} \mathrm{C}$. Then, the plates were blocked with Block Ace for $1 \mathrm{~h}$ at room temperature. Plasma samples from $\mathrm{CH}$ and LC patients and healthy controls (100 $\mu 1,1: 100$ dilution) were added to each well, followed by incubation for $2 \mathrm{~h}$ at room temperature. After washing three times with PBS containing $0.05 \%$ Tween-20 (PBST), Peroxidase-conjugated goat anti-human IgG (Jackson Immuno Research Laboratories, Inc., W. Baltimore, USA) was reacted for $30 \mathrm{~min}$. The plates were washed with PBST and developed with Stable Peroxide Substrate Buffer (Pierce, Rockford, IL) for $20 \mathrm{~min}$. After stopping the reaction with $1 \mathrm{M} \mathrm{H}_{2} \mathrm{SO}_{4}$, the absorbance was measured at $490 \mathrm{~nm}$. All plasma samples were measured in duplicate and were randomly dispensed into the plates.

Statistical analysis. The two-tailed Student's t-test was used to evaluate the statistical significance of differences in the data obtained by the ELISPOT assay. Unpaired MannWhitney $U$ tests were used for the evaluation of the significance of differences in the data obtained by ELISA. $\mathrm{P}<0.05$ was considered to denote significant difference. 
A

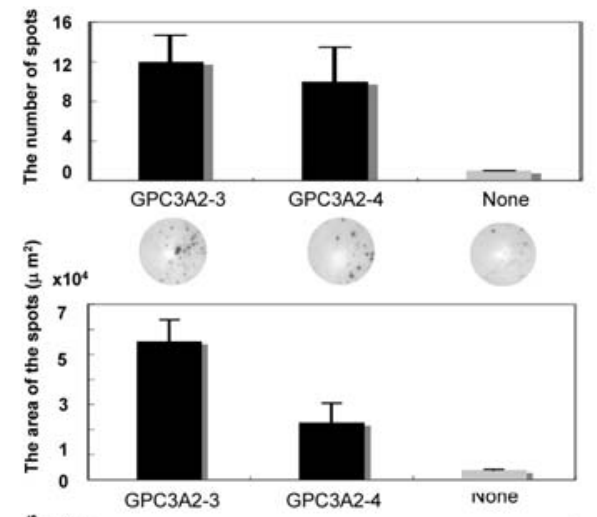

C

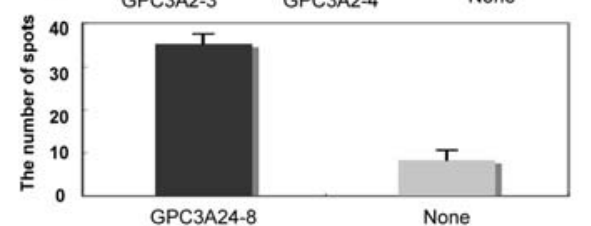

B

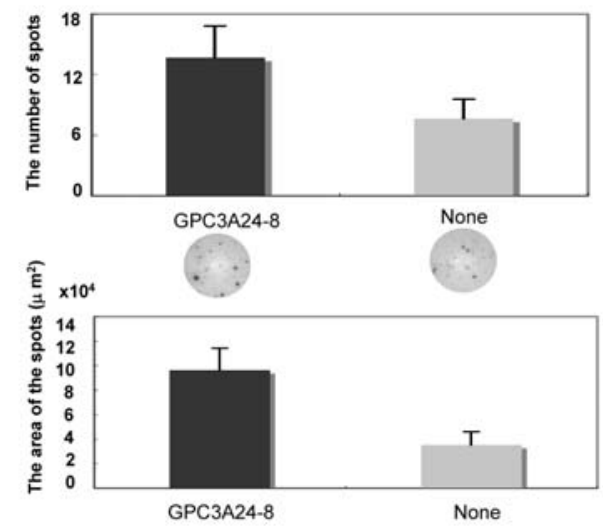

D

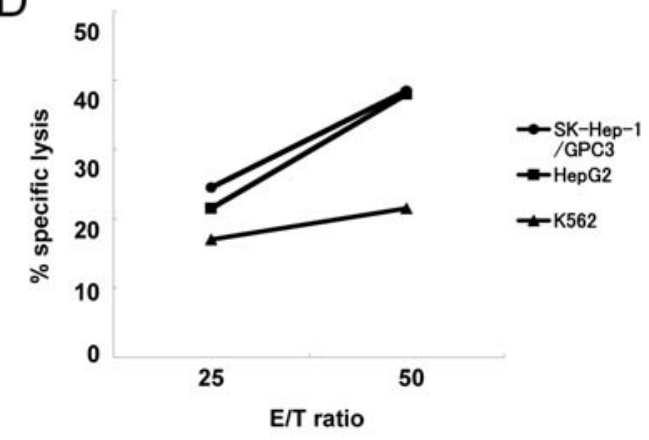

Figure 1. Frequency of GPC3-peptide-specific CTLs in the PBMCs of HLA-A2 ${ }^{+}$or HLA-A24+ $\mathrm{CH}$ and LC patients and the cytotoxicity of the CTLs induced by stimulation with the GPC3 (A2-3) peptide. GPC3-specific $\mathrm{CD}^{+} \mathrm{T}$ cells were detected in the chronic hepatitis [(A), HLA-A2 $2^{+} \mathrm{CH} 4$ patient; (B), HLA-A24 CH5 patient] and liver cirrhosis [(C), HLA-A24+ LC5 patient]. IFN- $\gamma$ produced by the peptide-specific T cells was measured by the IFN- $\gamma$-ELISPOT assay (middle column). The number and area of spots are shown in the upper and lower panels, respectively. Lysis of human hepatoma cell lines SK-Hep-1/GPC3 (circles) and HepG2 (squares) expressing GPC3 and HLA-A2 by GPC3-specific CTLs was observed following stimulation with the GPC3 A2-3 peptide (FVGEFFTDV) [(D), HLA-A2 ${ }^{+}$CH4 patient]. An HLA-classI- K562 human erythromyeloblastoid leukemia cell line was used as the negative control (triangles).

\section{Results}

Frequency of GPC3-peptide-specific CTLs in the PBMCs of $H L A-A 2^{+}$or HLA-A24+ $\mathrm{CH}, \mathrm{LC}$ and HCC patients. We evaluated the frequency of CTLs that recognized the GPC3 A2-1, A2-3, A2-4 or A24-8 peptide in the PBMCs of CH, LC and $\mathrm{HCC}$ patients. The $\mathrm{CH}$ and $\mathrm{LC}$ patients enrolled in this study were 34 male and 22 female patients. The average age of the patients was 64 years. HCV and HBV infection was found in 54 and 2 patients, respectively. The 56 patients were $33 \mathrm{CH}$ and $23 \mathrm{LC}$ cases. Mean serum $\alpha$-fetoprotein (AFP) was $13.3 \pm 21.1 \mathrm{ng} / \mathrm{ml}$ (normal $<20 \mathrm{ng} / \mathrm{ml}$ ). In regard to the HLA genotype, 10, 22 and 13 patients, respectively, were HLA-A2 ${ }^{+}$, HLA-A $24^{+}$and HLA-A2 $2^{+} / 24^{+}$. On the other hand, there were 11 patients who were HLA-A2\%A24- In this investigation, we enrolled the 45 patients who were HLA$\mathrm{A} 2^{+}$or HLA-A $24^{+}$.

We determined the presence of CTLs in the PBMCs of the $\mathrm{CH}$ and LC patients by ELISPOT assay using HLA-A24and HLA-A2-restricted GPC3 peptides (Fig. 1, Table I). The representative data of the ELISPOT assay are highlighted. Interestingly, in the $\mathrm{CH} 4$ patient, the spots and areas were highly developed in the GPC3 A2-3 and A2-4 peptidestimulated PBMCs (Fig. 1A). However, few spots and areas were detected in the negative control (no peptide). In addition, GPC3 A24-8 peptide-restricted CTLs were also detected in the CH5 and LC5 patients (Fig. 1B and C). These results suggest that GPC3-specific CTLs are present in the PBMCs of some of $\mathrm{CH}$ and $\mathrm{LC}$ patients.

Cytotoxicity of CTLs induced by stimulation with the GPC3 (A2-3) peptide. To clarify the cytotoxic activity of GPC3specific CTLs induced by stimulation with the GPC 3 peptide, the HCC cell line, SK-Hep-1/GPC3, transfected with GPC3 and expressing HLA-A2 and HLA-A24 were used as the target cells (Fig. 1D). The CTLs induced from the PBMCs of $\mathrm{CH} 4$ (Table I) patient by stimulation with the GPC3 A2-3 peptide showed specific cytotoxicity against the SK-Hep-1/ GPC3 and HepG2 cells. On the other hand, no GPC3-specific cytotoxicity was observed against the HLA-classI- K562 cells. These results indicate that GPC3-peptide-specific CTLs induced from $\mathrm{CH} 4$ (Table I) patient are cytotoxic against the GPC3-expressing target HCC cells.

Frequency of $\mathrm{HLA}-\mathrm{A2} 2^{+}$or HLA-A24+ $\mathrm{CH}, \mathrm{LC}$ and $\mathrm{HCC}$ patients positive for GPC3-peptide-specific CTLs in PBMC The frequency of patients with GPC3-specific CTLs in their PBMCs is shown in Fig. 2, while the clinical backgrounds of the CH, LC and HCC patients are summarized in Table II. CTL positivity was observed in 5 of $26 \mathrm{CH}$ patients (19\%), 5 of 19 LC patients (26\%), and 21 of 54 HCC patients (39\%). In addition, the percentage of CTL-positive patients tended to 


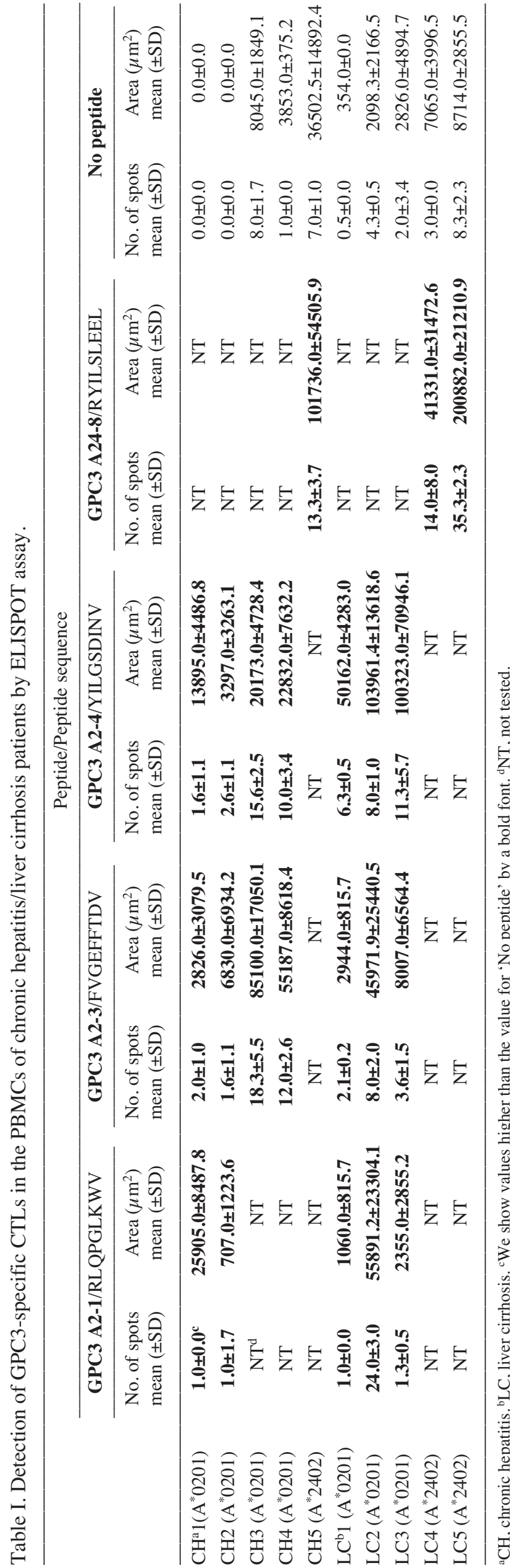

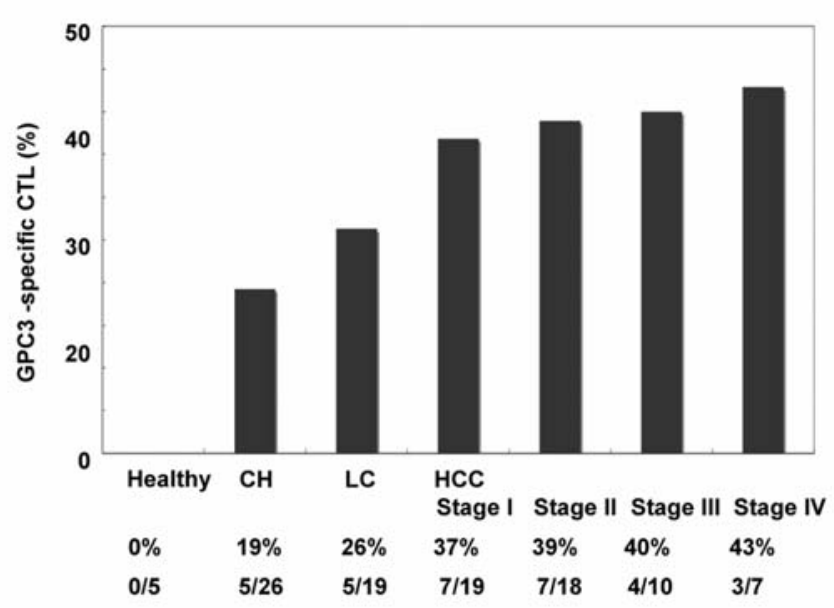

Figure 2. Frequency of HLA-A2 ${ }^{+}$or HLA-A24 ${ }^{+} \mathrm{CH}, \mathrm{LC}$ and $\mathrm{HCC}$ patients positive for GPC3-peptide-specific CTLs in the PBMCs. GPC3-peptidespecific CTLs were detected in 19 and $26 \%$ of the patients with $\mathrm{CH}$ and LC, respectively. In the HCC patients, the percentage of these CTLs tended to increase with increasing stage of progression of the disease: $37 \%$ (stage I), $39 \%$ (stage II), $40 \%$ (stage III) and $43 \%$ (stage IV).

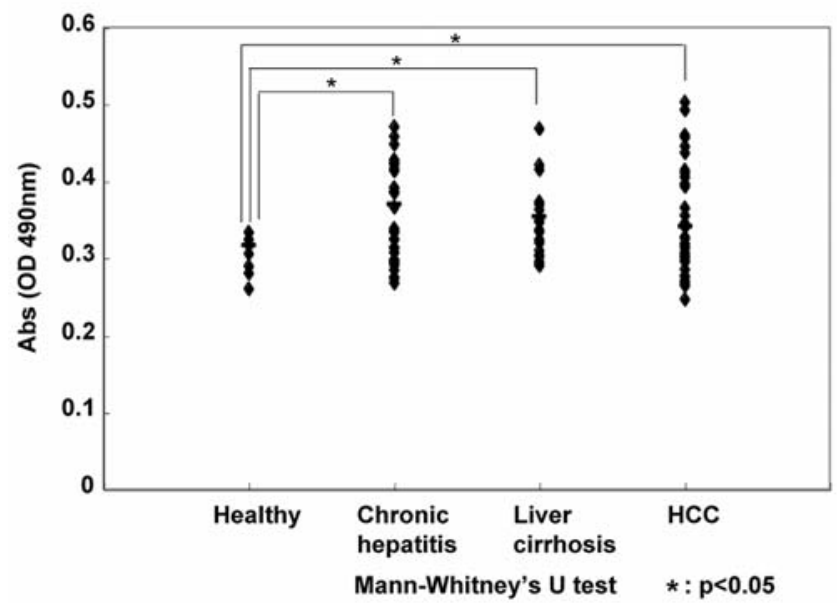

Figure 3. Plasma titers of anti-GPC3 $\mathrm{IgG}$ in the $\mathrm{CH}, \mathrm{LC}$ and $\mathrm{HCC}$ patients. Anti-GPC 3 IgG was detected by ELISA using recombinant GPC 3 protein. A significantly higher titer of IgG to GPC 3 was observed in the $\mathrm{CH}(\mathrm{p}<0.05)$, LC $(p<0.05)$ and HCC patients $(\mathrm{p}<0.05)$ as compared with that in healthy donors. " $\mathrm{p}<0.05$ (Mann-Whitney U test).

increase with increasing clinical stage of HCC; stage I (7/19, $37 \%)$, stage II $(7 / 18,39 \%)$, stage III $(4 / 10,40 \%)$, and stage IV $(3 / 7,43 \%)$ (Table II). There were no CTL-positive cases $(0 / 5,0 \%)$ in healthy donors.

Anti-GPC3 IgG in the plasma in patients with $C H, L C$ and $H C C$. To examine the quantitative titers of anti-GPC $3 \mathrm{IgG}$ in the plasma of patients with $\mathrm{CH}, \mathrm{LC}$ and $\mathrm{HCC}$, we carried out ELISA using the recombinant GPC3 protein (Fig. 3). The titers in the $\mathrm{CH}, \mathrm{LC}$ and $\mathrm{HCC}$ patients were significantly higher as compared with the peak titer in healthy controls. These results indicate that the GPC 3 antigen is expressed not only in HCC patients, but also in $\mathrm{CH}$ and $\mathrm{LC}$ patients. 
Table II. Number of CTL-negative and -positive cases in chronic hepatitis, liver cirrhosis and HCC patients.

\begin{tabular}{|c|c|c|c|c|c|c|c|c|}
\hline \multirow[b]{2}{*}{ Group } & \multicolumn{2}{|c|}{ Healthy $(n=5)$} & \multicolumn{2}{|c|}{ Chronic hepatitis $(n=33)$} & \multicolumn{2}{|c|}{ Liver cirrhosis $(n=23)$} & \multicolumn{2}{|c|}{$\mathrm{HCC}(\mathrm{n}=54)$} \\
\hline & $\begin{array}{c}\text { Negative }(n=5) \\
\text { mean }( \pm S D)\end{array}$ & $\begin{array}{c}\text { Positive }(\mathrm{n}=0) \\
\text { mean }( \pm \mathrm{SD})\end{array}$ & $\begin{array}{l}\text { Negative }(n=28) \\
\text { mean }( \pm S D)\end{array}$ & $\begin{array}{l}\text { Positive }(n=5) \\
\text { mean }( \pm S D)\end{array}$ & $\begin{array}{c}\text { Negative }(n=19) \\
\text { mean }( \pm S D)\end{array}$ & $\begin{array}{c}\text { Positive }(n=5) \\
\text { mean }( \pm S D)\end{array}$ & $\begin{array}{l}\text { Negative }(n=33) \\
\text { mean }( \pm S D)\end{array}$ & $\begin{array}{c}\text { Positive }(\mathrm{n}=21) \\
\text { mean }( \pm \mathrm{SD})\end{array}$ \\
\hline Age & $31.2 \pm 7.1$ & - & $61.6 \pm 11.2$ & $60.6 \pm 12.9$ & $67.3 \pm 10.1$ & $71.0 \pm 2.7$ & $65.8 \pm 7.9$ & $64.0 \pm 10.5$ \\
\hline Male & 4 & 0 & 16 & 3 & 12 & 3 & 28 & 15 \\
\hline Female & 1 & 0 & 12 & 2 & 6 & 2 & 5 & 6 \\
\hline \multicolumn{9}{|l|}{$\mathrm{HCV} / \mathrm{HBV}$} \\
\hline$+/-$ & ND & ND & 5 & 26 & 18 & 5 & 18 & 14 \\
\hline$-/+$ & ND & ND & 2 & 0 & 0 & 0 & 4 & 2 \\
\hline$+/+$ & ND & ND & 0 & 0 & 0 & 0 & 2 & 2 \\
\hline$-/-$ & ND & ND & 0 & 0 & 0 & 0 & 9 & 3 \\
\hline $\mathrm{AFP}(\mathrm{ng} / \mathrm{ml})$ & ND & ND & $9.5 \pm 18.9$ & $9.6 \pm 7.3$ & $21.2 \pm 25.4$ & $8.8 \pm 7.7$ & $26335.1 \pm 143782.5$ & $1431.5 \pm 3574.9$ \\
\hline \multicolumn{9}{|l|}{ HLA- } \\
\hline $\mathrm{A} 02^{+}$ & 3 & 0 & 3 & 3 & 2 & 2 & 13 & 8 \\
\hline $\mathrm{A} 24^{+}$ & 2 & 0 & 12 & 1 & 7 & 2 & 18 & 11 \\
\hline $\mathrm{A} 02^{+} / 24^{+}$ & 0 & 0 & 6 & 1 & 5 & 1 & 2 & 2 \\
\hline $\mathrm{A} 02^{-} / 24^{-}$ & 0 & 0 & 7 & 0 & 4 & 0 & 0 & 0 \\
\hline
\end{tabular}

\section{Discussion}

The oncofetal antigen GPC3 is known to be overexpressed in HCCs (3-10) and melanomas $(6,8,9)$. We recently identified GPC3-specific peptides restricted to HLA-A24 (A*2402) and $\mathrm{H}-2 \mathrm{~K}^{\mathrm{d}}$, or HLA-A2 (A*0201), both of which can induce GPC3-reactive cytotoxic T cells (CTLs) (19). We are currently conducting a phase I clinical trial of peptide vaccine prepared using these peptides against advanced HCC. In addition, in the near future, we propose to carry out a phase II clinical trial of the vaccine in $\mathrm{HCC}$ patients as well as $\mathrm{CH}$ and LC patients to evaluate its efficacy in preventing the onset of HCC. We report the finding of GPC3-specific CTLs in $\mathrm{CH}$ and $\mathrm{LC}$ patients for the first time in this study. Furthermore, the plasma titers of anti-GPC3 $\mathrm{IgG}$ in the $\mathrm{CH}$ and LC patients were also found to be significantly increased as compared with those in healthy donors.

It has been suggested that GPC3-specific CTLs may be derived from clinically invisible pre-neoplastic or neoplastic nodular lesions. In previous studies, expression of GPC3 was reported in $2 / 23(8 \%)$ cirrhotic low-grade dysplastic nodules, and 2/9 (22\%) (24), 2/22 (9\%) (25) or 6/31 (19\%) high-grade dysplastic nodules (26). In one study, among 5 adenomas with malignant characteristics, $3(60 \%)$ showed immunoreactivity for GPC3 in the malignant regions (24). Other studies reported positive staining for GPC 3 in 12/20 (60\%) (24) and 22/32 (69\%) cases (25) of early HCC. Meanwhile, the serum titers of the elevated GPC 3 antigen in HCC cases were reported to be correlated with the clinical stage of HCC (19). In our study, we noted an increase of the plasma titers of anti-GPC3 IgG antibody in CH, LC and HCC patients. In addition, the frequency of patients with GPC3specific CTLs appeared to increase with the stage of progression of the liver disease. These results suggest that GPC3 expression and the appearance of GPC3-specific CTLs may be prediagnostic markers of HCC.

On the other hand, the increase in the frequency of GPC3specific CTLs and titers of anti-GPC3 IgG in the peripheral blood might be related to the expression of GPC3 in $\mathrm{CH}$ with high grade inflammation and LC. In this study, we did not perform immunohistochemical examination for GPC3, because needle biopsy of the liver in our patients was not conducted in our collaborative clinic. Previous studies have demonstrated GPC3 expression by immunohistochemistry in 25/30 (83\%) cases of $\mathrm{CH}$ with high grade inflammation (27) and 11/95 (12\%) cases of LC (26), indicating that GPC3 might be expressed in $\mathrm{CH}$ with high-grade inflammation and some LC patients, resulting in the appearance of GPC3-specific CTLs in the PBMCs of these patients.

During the 1-year follow-up of this study, onset of HCC was not observed in any of the $10 \mathrm{CH}$ and LC patients who were positive for GPC3-specific CTLs in the peripheral blood; on the other hand, 2 (1CH and 1LC) patients who were negative for GPC3-specific CTLs showed development of HCC. It would, therefore, seem that the GPC3-specific CTLs might prevent the development of HCC or be predictive of a favorable prognosis of non-neoplastic liver lesions. However, our examination was limited to only HLA-A24and A2-positive patients, and moreover, we followed up the patients for only one year. Therefore, careful long-term observation of a larger number of $\mathrm{CH}$ and $\mathrm{LC}$ cases is necessary to determine the role of GPC3-specific CTLs in patients with $\mathrm{CH}$ and $\mathrm{LC}$.

In this study, we demonstrated an increase of GPC3specific CTLs and high titers of anti-GPC3 IgG in $\mathrm{CH}$ and LC patients. Thus, GPC3-specific CTLs and anti-GPC3 IgG 
may possibly be markers of early imaging-invisible HCC. In addition, active immunotherapy using GPC3 peptides may prevent the development of both non-neoplastic and neoplastic lesions of the liver.

\section{Acknowledgements}

We thank Ms. Chinatsu Kojima for her help with the preparation of this manuscript. This study was supported in part by Health and Labor Sciences Research Grants for Research on Hepatitis from the Ministry of Health, Labour and Welfare, Japan, and a Grant-in-Aid for the Third-Term Comprehensive 10-Year Strategy for Cancer Control from the Ministry of Health, Labour and Welfare, Japan, the Foundation for Promotion of Cancer Research in Japan, the Japan Research Foundation for Clinical Pharmacology, and a Research Resident Fellowship from the Foundation for Promotion of Cancer Research, Japan (E.H.).

\section{References}

1. Schafer DF and Sorrell MF: Hepatocellular carcinoma. Lancet 353: 1253-1257, 1999.

2. Tung-Ping Poon R, Fan ST and Wong J: Risk factors, prevention, and management of postoperative recurrence after resection of hepatocellular carcinoma. Ann Surg 232: 10-24, 2000.

3. Hippo Y, Watanabe K, Watanabe A, et al: Identification of soluble NH2-terminal fragment of glypican-3 as a serological marker for early-stage hepatocellular carcinoma. Cancer Res 64: 2418-2423, 2004.

4. Capurro M, Wanless IR, Sherman M, et al: Glypican-3: a novel serum and histochemical marker for hepatocellular carcinoma. Gastroenterology 125: 89-97, 2003.

5. Nakatsura T, Yoshitake Y, Senju S, et al: Glypican-3, overexpressed specifically in human hepatocellular carcinoma, is a novel tumor marker. Biochem Biophys Res Commun 306: 16-25, 2003.

6. Nakatsura T, Kageshita T, Ito S, et al: Identification of glypican-3 as a novel tumor marker for melanoma. Clin Cancer Res 10: 6612-6621, 2004.

7. Zhu ZW, Friess H, Wang L, et al: Enhanced glypican-3 expression differentiates the majority of hepatocellular carcinomas from benign hepatic disorders. Gut 48: 558-564, 2001.

8. Ikuta Y, Nakatsura T, Kageshita T, et al: Highly sensitive detection of melanoma at an early stage based on the increased serum secreted protein acidic and rich in cysteine and glypican-3 levels. Clin Cancer Res 11: 8079-8088, 2005.

9. Nakatsura T and Nishimura Y: Usefulness of the novel oncofetal antigen glypican-3 for diagnosis of hepatocellular carcinoma and melanoma. BioDrugs 19: 71-77, 2005.

10. Nakatsura T, Komori H, Kubo T, et al: Mouse homologue of a novel human oncofetal antigen, glypican-3, evokes T-cellmediated tumor rejection without autoimmune reactions in mice. Clin Cancer Res 10: 8630-8640, 2004.
11. Filmus J, Capurro M and Rast J: Glypicans. Genome Biol 9: 224, 2008.

12. Song HH, Shi W, Xiang YY, et al: The loss of glypican-3 induces alterations in Wnt signaling. J Biol Chem 280: 2116-2125, 2005.

13. De Cat B, Muyldermans SY, Coomans C, et al: Processing by proprotein convertases is required for glypican-3 modulation of cell survival, Wnt signaling, and gastrulation movements. J Cell Biol 163: 625-635, 2003.

14. Capurro MI, Xu P, Shi W, et al: Glypican-3 inhibits Hedgehog signaling during development by competing with patched for Hedgehog binding. Dev Cell 14: 700-711, 2008.

15. Grisaru S, Cano-Gauci D, Tee J, et al: Glypican-3 modulates BMP- and FGF-mediated effects during renal branching morphogenesis. Dev Biol 231: 31-46, 2001.

16. Lai JP, Sandhu DS, Yu C, et al: Sulfatase 2 up-regulates glypican 3, promotes fibroblast growth factor signaling, and decreases survival in hepatocellular carcinoma. Hepatology 47: 1211-1222, 2008.

17. Midorikawa $\mathrm{Y}$, Ishikawa $\mathrm{S}$, Iwanari $\mathrm{H}$, et al: Glypican-3, overexpressed in hepatocellular carcinoma, modulates FGF2 and BMP-7 signaling. Int J Cancer 103: 455-465, 2003.

18. Kwack MH, Choi BY and Sung YK: Cellular changes resulting from forced expression of glypican-3 in hepatocellular carcinoma cells. Mol Cells 21: 224-228, 2006.

19. Komori H, Nakatsura T, Senju S, et al: Identification of HLAA2- or HLA-A24-restricted CTL epitopes possibly useful for glypican-3-specific immunotherapy of hepatocellular carcinoma. Clin Cancer Res 12: 2689-2697, 2006.

20. Motomura Y, Ikuta Y, Kuronuma T, et al: HLA-A2 and -A24restricted glypican-3-derived peptide vaccine induces specific CTLs: preclinical study using mice. Int J Oncol 32: 985-990, 2008.

21. Wadee AA, Paterson A, Coplan KA, et al: HLA expression in hepatocellular carcinoma cell lines. Clin Exp Immunol 97: 328-333, 1994.

22. Matsui M, Machida S, Itani-Yohda T, et al: Downregulation of the proteasome subunits, transporter, and antigen presentation in hepatocellular carcinoma, and their restoration by interferongamma. J Gastroenterol Hepatol 17: 897-907, 2002.

23. Muneta Y, Nagaya H, Minagawa Y, et al: Expression and onestep purification of bovine interleukin-21 (IL-21) in silkworms using a hybrid baculovirus expression system. Biotechnol Lett 26: 1453-1458, 2004.

24. Wang XY, Degos F, Dubois S, et al: Glypican-3 expression in hepatocellular tumors: diagnostic value for preneoplastic lesions and hepatocellular carcinomas. Hum Pathol 37: 1435-1441, 2006.

25. Di Tommaso L, Franchi G, Park YN, et al: Diagnostic value of HSP70, glypican 3, and glutamine synthetase in hepatocellular nodules in cirrhosis. Hepatology 45: 725-734, 2007.

26. Baumhoer D, Tornillo L, Stadlmann S, et al: Glypican 3 expression in human non-neoplastic, preneoplastic, and neoplastic tissues: a tissue microarray analysis of 4,387 tissue samples. Am J Clin Pathol 129: 899-906, 2008.

27. Abdul-Al HM, Makhlouf HR, Wang G, et al: Glypican-3 expression in benign liver tissue with active hepatitis C: implications for the diagnosis of hepatocellular carcinoma. Hum Pathol 39: 209-212, 2008. 